\author{
Military Technical College \\ Kobry El-Kobbah, \\ Cairo, Egypt.
}

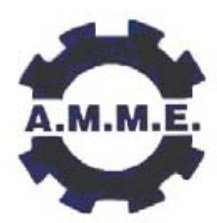

$13^{\text {th }}$ International Conference on Applied Mechanics and Mechanical Engineering.

\title{
DYNAMIC RESPONSE OF AN ADHASIVE BONDED JOINT FOR COMPOSITE STRUCTURE
}

\author{
GHONEAM $^{*}$ S. M., HAMADA ${ }^{*}$ A. A. and EL-ELAMY ${ }^{*}$ M. I.
}

\begin{abstract}
The dynamic response of boned joint for composite beam under pulse load was studied theoretically and experimentally. In the theoretical part, the validity of the theoretical model for evaluating natural frequencies, mode shape and dynamic response of boned joint composite beams at various types of bond line configuration has been examined by utilizing of the finite element technique. The finite element results indicated that the deformation mechanism of the boned joint composite beam depends on mechanical properties of the adhesive material. The mathematical finite element model is represented by introducing unified mechanical parameters to compute efficiently the Eigen-nature for composite bonded structures.

In the experimental part, the response of fiberglass-reinforced polyester composite specimens with various types of bond line configuration and five lamina orientations were measured by hammer test technique "frequency response function" (FRF).

The comparison between experimental and numerical model shows the efficiency of the proposed mathematical model of the composite structural beam with bonded joints. The results show that the changes of the dynamic response provide a proper indicator for predicting the current state of adhesive bonded joint.
\end{abstract}

\section{KEYWORDS}

Adhesive-bonded joint, finite element, response, composite structure.

* Department of Production Engineering and Mechanical Design, Faculty of Engineering, Menoufiya University, Shebin El-Kom, EGYPT 


\section{INTRODUCTION}

Adhesive-bonded joints have many advantages in terms of stress distribution, design flexibility, and simplicity of fabrication. Structural adhesives are engineering materials, and the adhesive bonding process is a recognized part of production engineering. However, as with other fastening methods, adhesive bonding, or more popularly, chemical welding has its advantages and limitations which must be considered by modern industrial designers and engineers when choosing between nailing, bolting, riveting, brazing, welding, or bonding to fasten parts together. Damages of various types often initiate and propagate in components made of fiber-reinforced composite materials during their service life. The presence of the damage results in degradation of the component mechanical properties (i.e. stiffness and fatigue properties) and increases its damping has studied by Nayeb-Hashemi et al. [1]. To assure structural integrity, damaged structural components should be replaced or repaired. However in many cases, the replacement of these components is impossible or costly. Consequently, composite repair has developed into an important technology to restore the strength, stiffness and durability of the damaged components was studied by Charalambides et al. [2].

He and Rao [3] developed an analytical model to study the coupled transverse and longitudinal vibration of a bonded lap joint system. The system consisted of a pair of parallel and identical beams were lap-jointed over a certain length by a viscoelastic material. The unjointed ends of the beams were assumed to be simply supported.

A mathematical model to study the longitudinal vibration of an adhesively bonded double-strap joint was presented by $\mathrm{He}$ and Rao [4]. The adhesive was modeled as a viscoelastic material using a complex modulus approach. Both the shear and longitudinal deformation in the adhesive layer were included in the analysis. The equations to predict the system resonance frequencies and loss factors were derived from the system natural and forced boundary conditions for the case of simply supported boundary conditions. A special searching strategy for finding the zeros of a complex determinant had been utilized, obtaining the numerical results. The effects of the adhesive shear modulus and structural parameters such as lap ratio and adhesive and strap thicknesses on the system resonance frequencies and loss factors were also studied by Roy and Reddy [5].

Khalil and Kagho [6] reported nondestructive testing of adhesively bonded joints using vibrational analysis. In this study, two types of artificial defect, voids and disbounds, were manufactured, both types of defect being made at different positions and having different sizes. These results indicated that both voids and disbounds could be detected by the reduction in the resonant frequencies and the increase in damping; however, it was difficult to locate the position of the defect and to estimate its size.

Dynamic response of adhesively bonded tubular joints subjected to a harmonic axial load was obtained by Vaziri et al. [7] as a function of adherends' mechanical properties and geometry, as well as the adhesive mechanical and damping properties. In addition, effects of defects, such as void in the overlap area, on the system dynamic response were investigated. Vaziri and Hashemi [8] studied theoretically and experimentally investigation on the dynamic response of repaired composite beams under a harmonic peeling load. 
Goto et al. [9] studied the frequency response of the five thermoplastic composites bonded by two kinds of epoxy resin. It was shown that vibration-damping properties increased by using flexible epoxy resin as adhesives. He and Rao [10] developed an analytical model to study vibration of bonded joints subjected to transverse loadings by considering both longitudinal and transverse displacements of the system. The equations of motion were developed using Hamiltonian principle. They obtained the system resonance frequencies, mode shapes and modal loss factors. However, there was no attempt to investigate the effects of the adherents and adhesive mechanical properties as well as defects in the lap area on the dynamic response of lap joints. Yuceoglu et al. [11] studied free bending vibrations of two rectangular orthotropic plates connected together by an adhesive layer in a single overlap configuration. The natural frequencies and corresponding mode shapes are obtained using Mindlin plate theory. It was found when the plate adherents were dissimilar; the upper plate experienced very different deflection shapes than those of the lower plate at least in the lower modes. In fact, one of the plates remained almost stationary, while the other, exhibited a dominant deflection shape.

The effects of bond geometry and adhesive properties on vibration response of single lap joints under harmonic peeling load were studied by Vaziri et al. [12]. Furthermore, the effects of a void in the lap joint, on the natural frequencies and damping behavior of the joint and peeling and shear stresses amplitude distribution were studied by Vaziri et al. [13]

In the present work, various specimens of laminated composite beam made of fiberglass are investigated. Each specimen was made of five plies for various bond line configurations for various code numbers via different boundary conditions within the overture frequency spectrum. The mathematical finite element models (F. E. M.) are developed to compute the eigen-nature for composite bonded structures. Modified mechanical parameters are introduced to raze the accuracy of developed model. The experimental analyses are investigated by utilizing the frequency response function using hammering method. The results show that the changes of the dynamic response provide a proper indicator for predicting the current state of adhesive bonded joint.

\section{MATERIAL}

Glass fiber is used as reinforcement in the form of bidirectional fabric (Standard EGlass Fiberglass) and polyester with catalyst addition as matrix for the composite material [14]. The adhesive bond material is Araldite 2015 (AV5308/HV 5309-1) that is two component epoxy paste adhesive. The mechanical properties of the composite are calculated analytically using the mixture rule [15]. The values used are shown in Table 1.

\section{MODEL ANALYSIS USING THE FINITE ELEMENT METHOD}

A typical composite beams of dimensions $(350 \times 40 \times 5) \mathrm{mm}$ with three bond line configurations (V, S \& W) were modeled in order to get a first estimation of the undamped natural frequencies and mode shapes for clamped-clamped boundary condition along with the edges of beams are shown in Fig.1. The equivalent elastic modulus and density of composite bonded joint beams are computed also various type of joint are employed [16]. A mesh element of $(20 \times 10)$ eight brick elements are utilized 
Table 1: Material properties (International System - SI)

\begin{tabular}{|c|l|c|c|c|}
\hline Material & \multicolumn{1}{|c|}{ Properties } & Symbol & Value & units \\
\hline & Elasticity Modulus & $\mathrm{E}_{\mathrm{f}}$ & $76.00 \times 10^{9}$ & {$\left[\mathrm{~N} / \mathrm{m}^{2}\right]$} \\
Glass & Density & $\rho_{\mathrm{f}}$ & $2.56 \times 10^{3}$ & {$\left[\mathrm{Kg} / \mathrm{m}^{3}\right]$} \\
Fiber & Poisson's coefficient & $U_{f}$ & 0.22 & \\
\hline \multirow{3}{*}{ Polyester } & Elasticity Modulus & $\mathrm{E}_{\mathrm{m}}$ & $4.00 \times 10^{9}$ & {$\left[\mathrm{~N} / \mathrm{m}^{2}\right]$} \\
& Density & $\rho_{\mathrm{m}}$ & $1.30 \times 10^{3}$ & {$\left[\mathrm{Kg} / \mathrm{m}^{3}\right]$} \\
& Poisson's coefficient & $\mathrm{U}_{\mathrm{m}}$ & 0.40 & \\
\hline & Elasticity Modulus Fiber & $\mathrm{E}_{11}$ & $44.8 \times 10^{9}$ & {$\left[\mathrm{~N} / \mathrm{m}^{2}\right]$} \\
& direction & $\mathrm{E}_{22}$ & $11.27 \times 10^{9}$ & {$\left[\mathrm{~N} / \mathrm{m}^{2}\right]$} \\
Composite & Normal to fiber & $\rho_{\mathrm{c}}$ & 1780 & {$\left[\mathrm{Kg} / \mathrm{m}^{3}\right]$} \\
material & Density & $\mathrm{G}_{12}$ & $4.86 \times 10^{9}$ & {$\left[\mathrm{~N} / \mathrm{m}^{2}\right]$} \\
& Shear Modulus & $U_{12}$ & 0.28 & \\
& Poisson's coefficient & $V_{f}$ & $60 \%$ & \\
& Fiber volume fraction & & & \\
\hline Adhesive & Elasticity Modulus & $\mathrm{E}$ & $1.98 \times 10^{9}$ & {$\left[\mathrm{~N} / \mathrm{m}^{2}\right]$} \\
(Araldite & Density & $\rho$ & $1.1 \times 10^{3}$ & {$\left[\mathrm{Kg} / \mathrm{m}^{3}\right]$} \\
2015 A/B) & Shear Modulus & $\mathrm{G}$ & $0.42 \times 10^{9}$ & {$\left[\mathrm{~N} / \mathrm{m}^{2}\right]$} \\
& Poisson's coefficient & $\mathrm{U}$ & 0.32 & \\
\hline
\end{tabular}

in the analysis and as shown in Fig. 1. The element has three degree of freedom at each $n$ ode: translation in the nodal $X, Y$ directions and rotation about the nodal $Z$ axis [17]. The model of adhesive bonded joint is modeled and represented as shown in Fig. 2.

The beam is constituted by five layers with different fiber orientations Set 1 : [0/0/0/0/0], Set2: [0/30/0/30/0], Set3: [0/45/0/45/0] Set4: [0/60/0/60/0] and Set5: [0/90/0/90/0], were fabricated by hand lay-up process followed by a cure process under pressure.

Once the problem has been discretized, the next step was to find the solution for the general dynamic problem equation:

$$
[M]\{\hat{a}\}+[C]\{\dot{a}\}+[K]\{a\}=\{F(t)\}
$$

The mass and stiffness matrix of the element can be then formulated as [18]:

$$
\begin{aligned}
& {[M]^{(\theta)}=\rho_{0} \int[N]^{T}[N] d x d y} \\
& {[K]^{(\theta)}=\int[B]^{T}[D][B] d x d y}
\end{aligned}
$$

where, $\rho_{c}$ is the density of composite beam with bonded joint; $[\mathrm{N}]$ is the matrix of shape function, $[B]$ is strain matrix and $[D]$ is the elasticity matrix of composite beam, which can computed as [19], for different code number, various degree of constraints at the medium ratio of fiber volume friction $\left(V_{f}=60 \%\right)$. Here the equivalent flexural coefficient of the stiffness matrix of laminated layer is expressed as [20]: 


$$
D_{i j}=\frac{1}{3} \sum_{k=0}^{n} \bar{Q}_{i j}\left(h_{k}^{3}-h_{k-1}^{3}\right)
$$

where $\mathrm{n}$ is the number of layers, $\bar{Q}_{i j}$ is the transformed reduced stiffness, $\mathrm{h}_{\mathrm{k}}$ is the thickness of the $k^{\text {th }}$ layer and $i, j$ are indices varying from $1,2 \& 6$.

$$
[D]^{-1}=\left[\begin{array}{cccccc}
1 / E_{x} & -v_{x y} / E_{x} & -v_{x z} / E_{x} & 0 & 0 & 0 \\
-v_{x y} / E_{x} & 1 / E_{y} & -v_{y z} / E_{x} & 0 & 0 & 0 \\
-v_{z x} / E_{x} & -v_{z y} / E_{x} & 1 / E_{z} & 0 & 0 & 0 \\
0 & 0 & 0 & 1 / G_{x y} & 0 & 0 \\
0 & 0 & 0 & 0 & 1 / G_{y z} & 0 \\
0 & 0 & 0 & 0 & 0 & 1 / G_{x z}
\end{array}\right]
$$

and $[\mathrm{C}]^{(\mathrm{e})}$ which depends on the damping model adopted.

The assembly of the global matrices, next step for the solution of the problem, is done by the package using the equation. For the determination of the natural frequencies of a undamped system with $\mathrm{N}$ degrees of freedom, the solution is sought by solving: [18]

Then,

$$
[M]_{N \times N}(\delta]_{N \times 1}+[K]_{N \times N}[\delta]_{N \times 1}=0
$$

$$
\left[-\tilde{U}_{r}^{2}[M]+\lceil K\rceil\right]\{V\}=0
$$

The Eigen-values and mode shapes are computed using the FM soft ware package ANSYS (Version 5.4). Initially the beams were modeled in order to get a first estimation for the undamped natural frequencies and mode shape utilizing finite element type SOLID 6.5. The material properties were then entered in the program and the constraint imposed to simulate a type of fixation. The numerical results using FEM were computed for different bond line configurations and lamina orientation in the case of built in at two edges of beam.[17].

\section{EXPERIMENTAL INVESTIGATIONS}

\section{Specimen Manufacture}

The chopped composite laminates were manufactured using hand lay-up technique by using the manufacturing component. Five layers of $(610 \mathrm{~mm})$ long were spread on die plate at various orientation fibers shown in Fig. 3. A layer of resin was spread on a glass plate $(610 \times 310 \mathrm{~mm})$ treated by release agent (Wax or medical Vaseline). 
The layer of glass fiber was placed on the resin and consolidated using a suitable laminating roller until the mat is fully impregnated and all visible air inclusions were removed form the laminate. This procedure was repeated with alternate layers of resin and glass fiber until the build up was completed. The press plate $(610 \times 310 \mathrm{~mm})$ was placed on the glass plate and a weight of $50 \mathbf{~ K g}$ was placed on the press plate, [21]. To obtain approximately constant thickness $(5 \pm 0.1 \mathrm{~mm})$ for the composite laminate, a metal tap of $\mathbf{5} \mathbf{~ m m}$ thickness was placed between the two glass plates at each corner. The press plate and weight was removed after 24 hours and the laminate was completely cured at room temperature, $[22,23]$.

The laminate was cut to the required dimensions $(200 \times 50 \times 4 \mathrm{~mm})$ using sawing machines [22]. For making test specimens, the margins of the laminate, up to at least 5 $\mathbf{m m}$ from the edge, were cut and the working portions of the specimens were taken away from the edge by about $\mathbf{5} \mathbf{~ m m}$. The constituent materials of GFRP laminate were listed in Table 2. Figure 4 shows, to attach of bonded line configuration manufacture at $(\mathrm{V}, \mathrm{S} \& \mathrm{~W})$.

\section{Experimental Modal Analysis}

Through an impact experimental test, it was determined the FRFs (Frequency Response Function) which relate the response given by the specimen when loaded with a signal, allowing for the determination of the natural frequencies and the damping factors, as shown in Fig. 5. This was done by fixing the laminate specimen in a rigid support for two end of a bonded joint composite beam, vibrate the beam at mid-point. The impact hammer (piezoelectric cells B\&K, Type 8202) was used to give the input load (pulse) to the specimen, and the Spectral Analyzer was set from $0 \mathrm{~Hz}$ to $400 \mathrm{~Hz}$. This output was captured by the accelerometer (B\&K Model 4374 , mass $=2.4 \times 10^{-3} \mathrm{~kg}$ ) and together with the input sign were amplified (B\&K, Type 2835) using the spectrum analyzer BRUEL \& KJAER (B\&K, Type 2034) [17].

Since the specimens are very flexibility and light, have should be given to choose the accelerometer to avoid undesirable influences on the measurements.

\section{Dynamic Response Measurement}

The dynamic response of the bonded joint composite beams was obtained by clampedclamped the beam to a heavy stone table and striking the beam with impact hammer at its middle. A Frequency Response Function was utilized to record the transverse dynamic response of the composite beam at a middle point on the joint [8].

The damping matrix $[\boldsymbol{C}]$ can be calculating as a proportional damping (Rayleigh damping) as shown in Eq.8, where $\boldsymbol{\alpha}$ and $\boldsymbol{\beta}$ are coefficients determined by some experimental investigation. The necessary and sufficient conditions of proportional damping system are given by Eq. 9 In this case, the impulse response of the bonded joint system was separated into the responses at each mode by spectral analysis and the damping ratio $\xi_{i}$ and coefficients $\boldsymbol{\alpha}$ and $\boldsymbol{\beta}$ are identified by Eq. 10 [24]:

$$
[C]=\propto[M]+\beta[K]
$$


Table 2: The constituent materials of GERP laminate.

\begin{tabular}{|c|c|}
\hline Material & Type \\
\hline Matrix & Polyester 2504APT-S \\
& Hardener (peroxide $0.7 \%$ and Cobalt $0.6 \%$ by volume) \\
\hline Reinforcement & E-glass in various orientations fiber $\left(300 \mathrm{gm} / \mathrm{m}^{2}\right)$ \\
\hline
\end{tabular}

$$
\begin{aligned}
& {[C][K]^{-1}[M]=[M][K]^{-1}[C]} \\
& \xi_{i}=\frac{\pi}{2 \omega_{i}}+\frac{\beta \omega_{i}}{2}
\end{aligned}
$$

where $\xi_{i}$ and $\boldsymbol{\omega}_{i}$ are the damping ratio and natural frequency of $i^{\text {th }}$ mode and this parameters are listed in Table 3. The equation of motion of a damped multi degree of freedom system in matrix form:

$$
[M] \ddot{X}+[C] \dot{X}+[K] X=[F]
$$

By expressing the solution of $X$ as a linear combination of the natural modes of the undamped system as:

$$
X=x \cos (\omega t)
$$

By substituting Eq. 12 into Eq. 11, we obtain

$$
x=\left[-\omega^{2}[M]+j \omega[C]+[K]\right]^{-1} F
$$

\section{RESULTS AND DISCUSSION}

The dynamic response of bonded joint for composite beam under pulse load was investigated experimentally. Table (3) shows the variation of fundamental and second frequencies, associated with damping factor for different code number and bond line configurations at the same beam thickness and fixation. It can be seen that the damping factor of specimen [0/90]5 is relatively high compared with the other, this due to maximum dissipated energy at this lamina orientation at bond line configuration [W]. Also it can be noticed that the damping factor of [0]5 is relatively low compared with the other duo to high stiffness value at this case of lamina orientation.

Figure (6) shows dynamic response of the adhesively bonded joint for composite structures at $\mathrm{V}, \mathrm{S}$ and $\mathrm{W}$ bond line configurations. Determination of the dynamic response, frequencies and damping factor of a vibrating structure is an important aspect from the stand point of view of the structure dynamic behavior. The natural frequency gives information about resonance avoidance for certain loading conditions. Mode shape, on the other hand gives indication about the vibration level at each position of structure. One of the most important parameters from designer's point of view is the location of nodes and antinodes. The nodes are the positions at which the 
Table 3: The damping factors, natural frequency and coefficients $\boldsymbol{\alpha}$ and $\boldsymbol{\beta}$ (Experimental result).

\begin{tabular}{|c|c|c|c|c|c|c|c|}
\hline \multicolumn{2}{|c|}{$\begin{array}{c}\text { Bond line } \\
\text { configurations } \\
\text { \&Orientations }\end{array}$} & $\xi 1$ & $\xi 2$ & $\omega_{1}, r / s$ & $\omega_{2}, r / s$ & $\alpha$ & $\beta$ \\
\hline \multirow{4}{*}{$\mathrm{V}$} & {$[0 / 0 / 0 / 0 / 0]$} & 0.061 & 0.053 & 496.1 & 1670.5 & 49.24 & $4.6 \times 10^{-5}$ \\
& {$[0 / 30 / 0 / 30 / 0]$} & 0.105 & 0.101 & 489.8 & 1626.5 & 80.36 & $9.4 \times 10^{-5}$ \\
& {$[0 / 45 / 0 / 45 / 0]$} & 0.134 & 0.128 & 471.0 & 1588.6 & 99.20 & $1.2 \times 10^{-4}$ \\
& {$[0 / 60 / 0 / 60 / 0]$} & 0.169 & 0.162 & 458.4 & 1544.1 & 121.6 & $1.6 \times 10^{-4}$ \\
& {$[0 / 90 / 0 / 90 / 0]$} & 0.196 & 0.190 & 439.6 & 1513.5 & 135.2 & $1.9 \times 10^{-4}$ \\
\hline \multirow{6}{*}{$\mathrm{S}$} & {$[0 / 0 / 0 / 0 / 0]$} & 0.095 & 0.087 & 483.5 & 1657.9 & 73.60 & $7.8 \times 10^{-5}$ \\
& {$[0 / 30 / 0 / 30 / 0]$} & 0.127 & 0.122 & 477.2 & 1613.9 & 95.41 & $1.1 \times 10^{-4}$ \\
& {$[0 / 45 / 0 / 45 / 0]$} & 0.156 & 0.150 & 458.4 & 1576.3 & 112.6 & $1.4 \times 10^{-4}$ \\
& {$[0 / 60 / 0 / 60 / 0]$} & 0.199 & 0.191 & 445.8 & 1532.3 & 139.7 & $1.8 \times 10^{-4}$ \\
& {$[0 / 90 / 0 / 90 / 0]$} & 0.243 & 0.236 & 420.7 & 1494.6 & 161.4 & $2.4 \times 10^{-4}$ \\
\hline \multirow{5}{*}{$\mathrm{W}$} & {$[0 / 0 / 0 / 0 / 0]$} & 0.112 & 0.107 & 477.2 & 1339.1 & 84.32 & $9.9 \times 10^{-5}$ \\
& {$[0 / 30 / 0 / 30 / 0]$} & 0.144 & 0.136 & 464.7 & 1588.9 & 105.9 & $1.3 \times 10^{-4}$ \\
& {$[0 / 45 / 0 / 45 / 0]$} & 0.197 & 0.191 & 439.6 & 1544.9 & 136.5 & $1.9 \times 10^{-4}$ \\
& {$[0 / 60 / 0 / 60 / 0]$} & 0.227 & 0.220 & 427.0 & 1507.2 & 152.9 & $2.2 \times 10^{-4}$ \\
& {$[0 / 90 / 0 / 90 / 0]$} & 0.287 & 0.281 & 408.2 & 1475.8 & 185.0 & $2.9 \times 10^{-4}$ \\
\hline
\end{tabular}

vibration vanishes, the maximum stresses induced at these nodes. While the antinodes are the positions at which maximum vibration level occurs.

From the previous discussion it can be seen that the frequency of specimen [0/90]5 at $\boldsymbol{W}$-Joint is lower than those of the other specimen, and specimen [0]5 at $\boldsymbol{V}$-Joint has higher ones. The natural frequencies in [ $\boldsymbol{V}]$ bond line configurations are $\mathbf{1 . 1}$ times greater than those in $[\boldsymbol{W}]$ bond line configurations. Changing the fiber lamina orientation from [0]5 to [0/90]5 decreases natural frequencies by almost $11 \%$. For instance, the natural frequencies at clamped-clamped ends fixation has $\mathbf{5 . 2}$ times greater than those in clamped-free ends fixation.

From the Table 6-3 the damping factor $\xi$ in [ $\mathbf{V}$ ]bond line configurations are decreasing by $\mathbf{4 6 \%}$ approximately compare than with [W]bond line configurations. Changing of the fiber lamina orientation from [0]5 to [0/90]5 increases damping factor by $69 \%$ approximately. In general case the maximum value of damping obtain at specimen $[0 / 90] 5, W$-Joint and clamped-free ends boundary fixation and minimum value obtain at specimen [0]5, $\boldsymbol{V}$-Joint at clamped-clamped ends.

Thus the frequency and damping factor level may be controlled by changing the bond line configuration, fiber lamina orientation angle and boundary fixations, and consequently the results obtained are beneficial for the designer in order to select the proper bond line configurations, fiber orientation and boundary fixation.

\section{CONCLUSIONS}

The dynamic response of laminated composite beam with different fiber orientations, 
bonded line configuration and boundary fixations are investigated experimentally. From the numerical and experimental results one can conclude:

1. The present comparison between the numerical and experimental results proves that the suggested finite element models of the composite structural beams with bonded joints provide an efficient tool for the dynamic analysis with proper accuracy.

2. The quasi uniform mass damping is inversely proportional to the stiffness of the bonded joint specimens. The rate of the proportionality depends mainly on the bond line configuration type, lamina orientation, and boundary conditions. This in turn provides the analysis with an efficient tool for accurate evaluation for selecting the proper criteria of the specimens for controlling the presented damping capacity and the proper resistance against deformation during the operating process.

3. The avoidance of rapid failure of the composite structures with bonded joint due to the longitudinal and transverse effect (particularly at the resonant modes) can be attained by selecting the proper bond line configuration type for example the composite beam with bond line type [W] and lamina orientation [0]5 and [0/90]5 is more convenient .

4. The present study provides an efficient non-destructive technique for the predication of dynamic properties for an adhesive bonded joint for the studied composite structure systems.

\section{REFERENCES}

[1] H. Nayeb-Hashemi, A. Harrison and A. Vaziri, "Dynamic response of a heat damaged fiber-resin beam subjected to harmonic forcing at the tip". J Compos Technol Res; Vol. 25 (2), pp. 87-95 (2003).

[2] M.N. Charalambides, R. Hardouin, A.J. Kinloch and F.L. Matthews "Adhesively bonded repairs to fiber-composite materials". I: experimental, Composites, Part A: Appl Sci Manuf; Vol. 29 (11), pp. 1371-1381, (1998).

[3] S. He and M.D. Rao, "Vibration analysis of adhesively bonded lap joint": Part 1, 2. Theory, Journal of Sound and Vibration; Vol. 152, pp. 405-501, (1990).

[4] S. He and M.D. Rao, "Longitudinal vibration and damping analysis of adhesively bonded double-strap joints", ASME Journal of Vibration and Acoustics; Vol. 114, pp. 330-342, (1992).

[5] S. Roy and N. Reddy, "Finite element models of viscoelasticity and diffusion in adhesively bonded joints", International Journal for Numerical Methods in Engineering; Vol. 26,pp 2531-2544, (1988).

[6] A.A. Khalil, and A.N. Kagho, "Non-destructive testing of adhesively bonded joints using vibrational analysis", International Journal of Adhesion and Adhesives; Vol. 11 (2), pp. 121-134, (1991).

[7] A. Vaziri, and H.N. Hashemi, "Dynamic response of tubular joints with an annular void subjected to a harmonic axial load", International Journal of Adhesion and Adhesives; Vol. 22, pp. 367-373, (2002).

[8] A. Vaziri1 and H. Nayeb-Hashemi, "Dynamic response of a repaired composite beam with an adhesively bonded patch under a harmonic peeling load", International Journal of Adhesion \& Adhesives; Vol. 26, pp. 314-324, (2006)

[9] Got, A., Matsude, M., Hamade, H., Maekawa, Y., Maekawa, Z., and Matuo, T., "Vibration Damping and Mechanical Properties of Continuous Fiber-Reinforced Various Thermoplastic Composites," Int. SAMPE Symp. Exh., Proc. Adv. Mat., May 10-13, Anaheim CA; Vol. 38 (2), pp. 1651-1665, (1993). 
[10] S. He and M. D. Rao, "Vibration Analysis of Adhesively Bonded Lap Joint. Part I: Theory", J. Sound Vib.; Vol. 152 (3), pp. 405-416, (1992).

[11] U.Yuceoglu, F.Toghi and O.Tekinalp, "Free Bending Vibration of Adhesively Bonded Orthotropic Plates with a Single Lap Joint", ASME J. Vibr. AcoustJan. New York NY; Vol. 118 (1), pp. 122-134, (1996).

[12] A.Vaziri, "Dynamic Response of Bonded Joints with Defects", Ph.D. Thesis, Part I, Dept. of Mechanical Eng., Northeastern University, Boston, MA 02115, (2003).

[13] Vaziri, A., Hamidzadeh, H. R., and Nayeb-Hashemi, H., "Dynamic Response of Bond Strength with Void Subjected to a Harmonic Peeling Load", J. Multibody Dynamics (Proc. Instn. Mech. Engrs. Part K); Vol. 215 (4), pp. 199- 206, (2001).

[14] V. Tita, J .de Carvalho, J. Lirani, "Theoretical and Experimental Dynamic Analysis of Fiber Reinforced Composite Beams", J. of the Braz. Soc. Mech. Sci. 7 Eng. XXV, Vol. 3, pp 306-310, (2003).

[15] Huntsman advanced materials (Europe) BVBA, B 3078 Everberg.

[16] M. R. Hatch, "Vibration Simulation Using Matlab and Ansys" Chapman and Hall/CRC, (2001).

[17] A. A. Hamada, S. M. Ghoneam and M. I. EL-Elamy, "Dynamic Analysis of an Adhesively Bonded Joint for Composite Structures", The $12^{\text {th }}$ International Conference on Aerospace Sciences and Aviation Technology (ASAT-12), Military Technical College, Cairo, Egypt, 29-31 May, (2007).

[18] V. Tita, J. de Carvalho and J. Lirani, "Theoretical and Experimental Dynamic Analysis of Fiber Reinforced Composite Beams", J. of the Braz. Soc. of Mech. Sci. \& Eng.; Vol. XXV (3), pp. 307-310, (2003).

[19] R. Chandra, S. Singh, K. Gupta, "A study of damping in fiber-reinforced composites", Journal of Sound and Vibration, Vol. 262, pp 475-496, (2003).

[20] R. M. Jones," Mechanics of composite materials", Scripta Book Company, (1975).

[21] BS3496, "Specification for a glass fiber chopped strand mat for reinforcement of polyester and other liquid laminating systems", 1989.

[22] ISO1268, "Fiber reinforced plastics and methods of producing test plates", 2001.

[23] U. Khashabu, "Some technological factor affecting the fatigue strength of FRP composites", Thesis of Doctor of Philosophy, Egypt, 1993.

[24] S. Morishita, D. Nomura and S. M. Ghoneam, "Vibration control of a pipe supported by a variable damper with gap", Asia-Pacific Vibration Conference, Kyongju, Korea, 13 November, (1997).

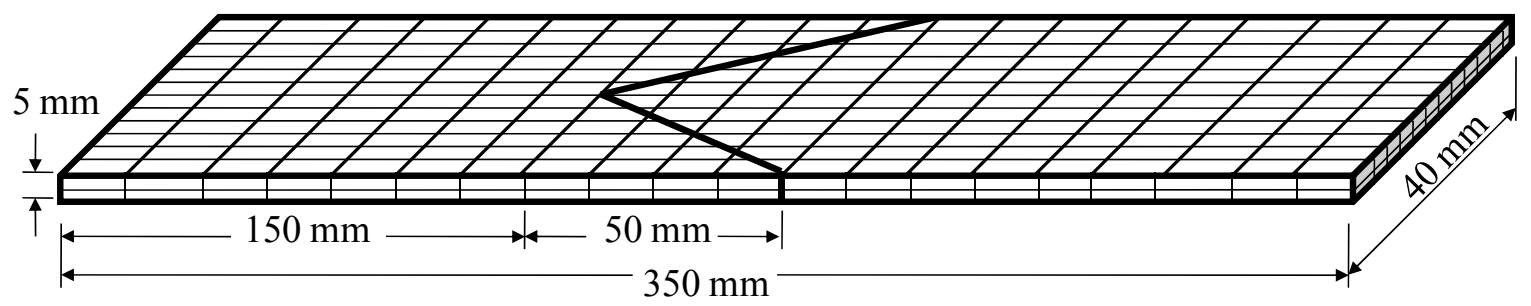

Fig. 1: Finite element model for bonded join. 


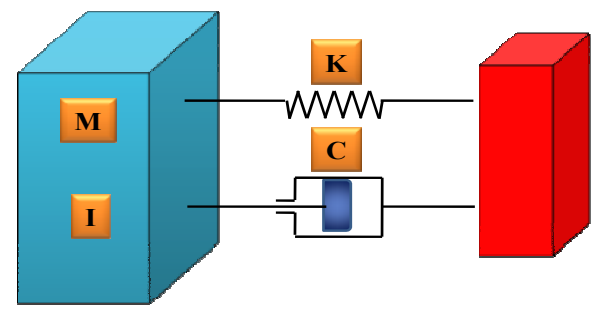

Fig. 2: Model of bonded joint

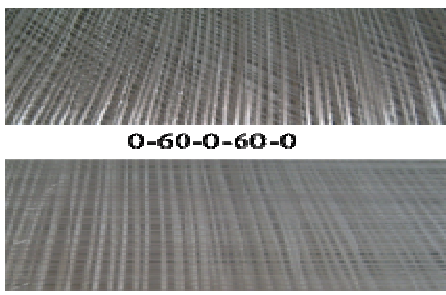

$0-90-0-90-0$

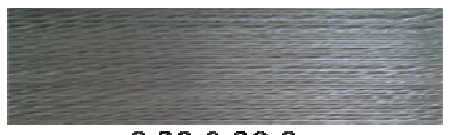

$0-30-0-30-0$

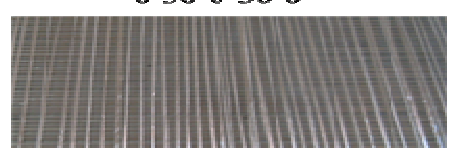

0-0-0-0-c

$0-45-0-45-0$

Fig. 3: Layer of various orientation fibers.

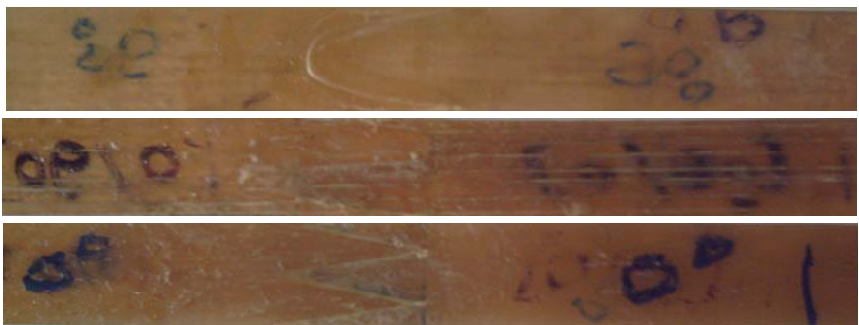

Fig. 4: Bond line joint configurations manufacture.

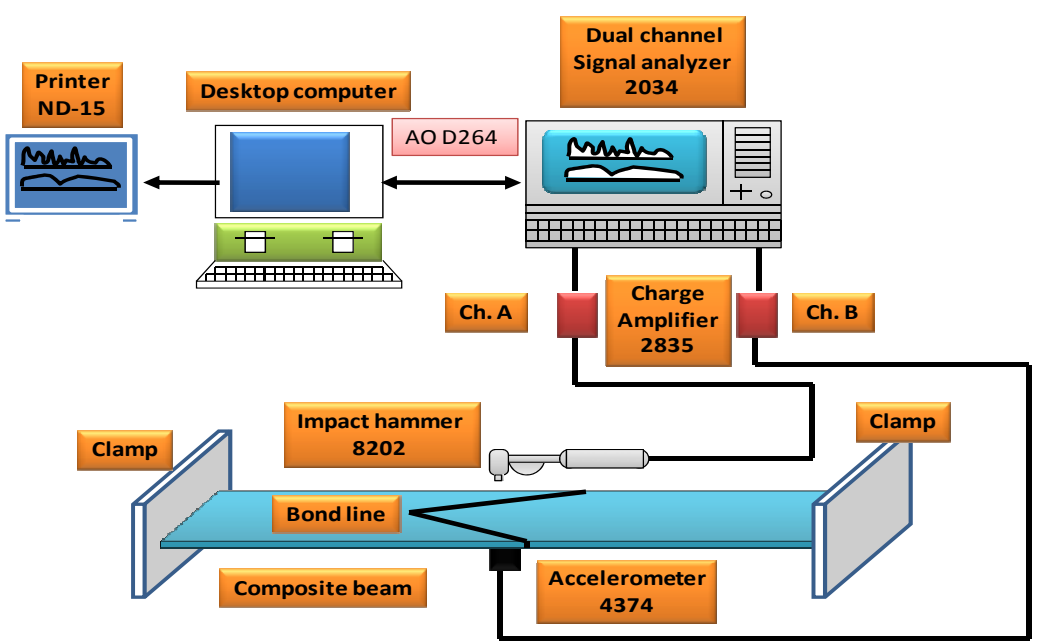

Fig.5: Experimental modal analysis. 

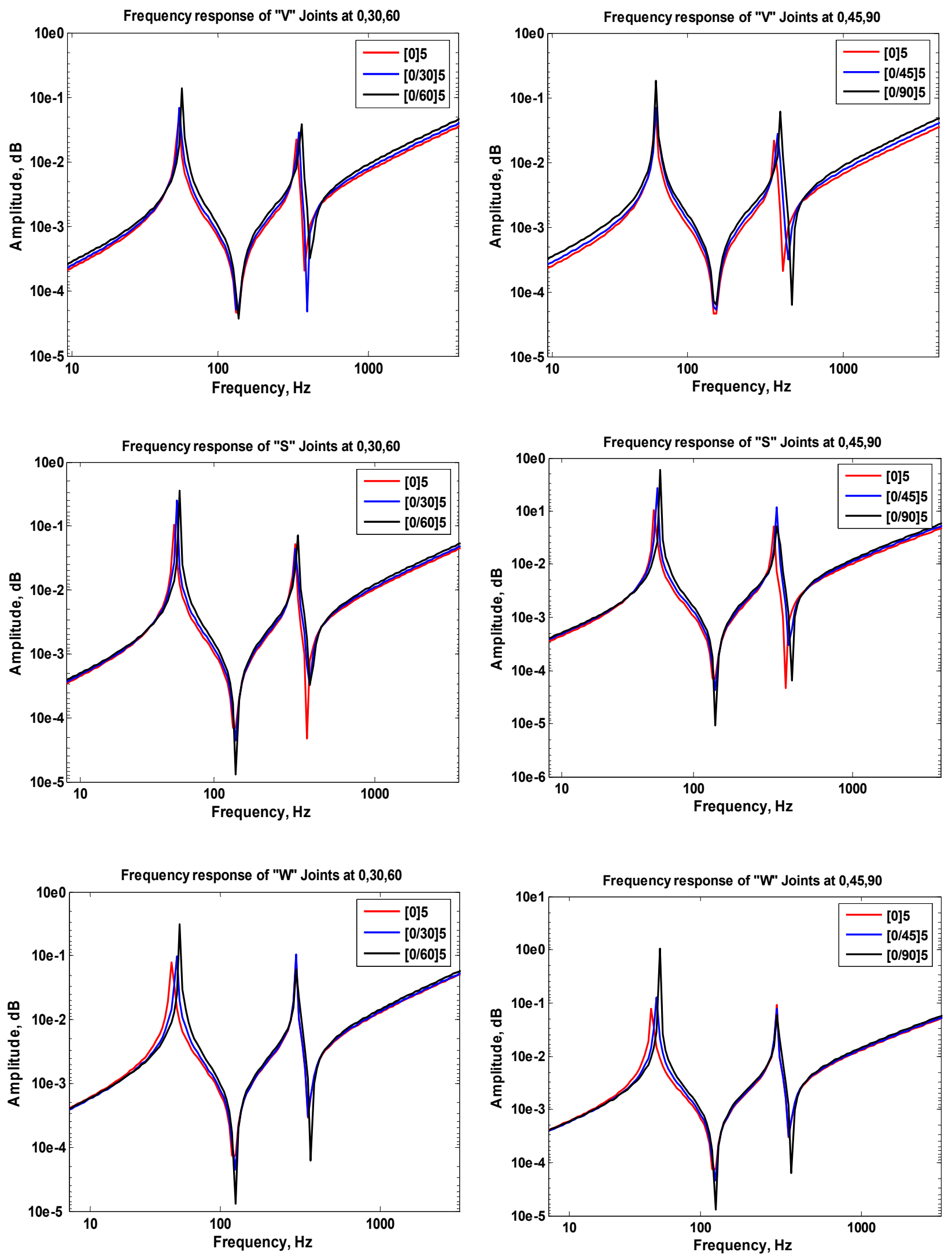

Fig. 6: The results of the theoretical model for the bending frequency response of the adhesively bonded joint for composite structures at $\mathrm{V}, \mathrm{S} \& \mathrm{~W}$ bond line configuration and various types of fiber lamina orientations. 